\title{
"El pueblo en llamas". Los orígenes y significados de las protestas populares de 1983 desde la memoria de los militantes del MAPU (Lautaro)*
}

\author{
Nicolás Acevedo Arriaza**
}

\section{La privatización de la política}

En 2011 las movilizaciones estudiantiles chilenas, lideradas por una nueva generación de jóvenes, generaron y revivieron grandes esperanzas en los sectores populares, además de grandes miedos en las 'elites políticas', tanto el gobierno de Sebastián Piñera como el conglomerado de oposición conocido como Concertación. Ambos bloques políticos fueron elaborando múltiples estrategias para encausar dichas expresiones, aspirando al retorno de la normalidad, mientras miles de estudiantes provocaban constantes paros y tomas de universidades y liceos, además de las masivas marchas por el centro de Santiago. El 'peak' de dicha movilización fue el 4 de agosto del 2011, cuando no se autorizó una marcha en la Alameda y hubo respuestas con "cacerolazos" (protestas con ruido generado por toques de ollas) en barrios y poblaciones del país. Camila Vallejo, dirigente de la Federación de Estudiantes de la

\footnotetext{
* Revisión en lengua española de Óscar Curros. Una primera versión fue presentada en XVII Congreso Internacional de Historia Oral, Buenos Aires, septiembre de 2012.

** Investigador Fondecyt. Equipo editorial Revista Pretérito Imperfecto.
} 
Universidad de Chile (FECH), acusó al gobierno de declarar un especie de 'estado de sitio', pasado oscuro que "muchos recuerdan, que no se quiere volver a repetir"; sin embargo, se alude al país de "hace treinta años atrás y, por más que hoy día se diga que hay una nueva forma de gobernar, parece una forma muy añeja, dictatorial, que se repite con los mismos que fueron autores y protagonistas de esos hechos de represión" (Camila Vallejo llama..., 2011). Esto dio cuenta de cómo el pasado reciente de nuestra historia ha continuado presente en la memoria tanto de adultos como de jóvenes en Chile. Una memoria que vuelve, retorna. Y por una causa actual. El llamado de movilización tuvo éxito aquel 4 de agosto debido a que miles de personas (de todas las edades), golpearon sus ollas tanto en Santiago como en otras ciudades del país. En las calles se volvía a escuchar el histórico canto de los ochenta, 'Y va a caer', que se refería a Augusto Pinochet; pero ahora se gritaba pidiendo que cayera 'su educación', su legado, el mismo que ha sobrevivido y ha sido perfeccionado a manos de la 'elite política' en este periodo llamado por algunos 'transición a la democracia'. Las protestas populares, que se habían generado con fuerza desde 1983, sobre todo en barrios populares y campos estudiantiles, resurgían en la memoria colectiva; aunque por nuevas reivindicaciones, que finalmente tenían que ver con el legado de la dictadura militar liderada por Augusto Pinochet.

La respuesta de la actual 'elite política' frente a las movilizaciones estudiantiles y populares fue finalmente de deslegitimar el rol 'político' de 'los actores sociales/estudiantiles'. La senadora 'designada' Ena Von Baer, ${ }^{1}$ hizo un llamado desesperado: "Los movimientos sociales ya pusieron las problemáticas sobre la mesa y ahora les toca a los liderazgos políticos alcanzar un acuerdo para realmente avanzar en las soluciones" (Edna Von Baer pide..., 2011). El senador socialista Camilo Escalona, consultado sobre la autonomía del movimiento estudiantil, planteó su visión actual de la "política" y de "lo político" a partir del recuerdo de 1982, durante la dictadura militar, cuando volvió clandestino de su exilio en Europa: "Viví las protestas nacionales dentro del país, el año ' 83 , en condiciones bastantes [sic] difíciles de reorganización de los partidos populares en nuestro país, bajo la dictadura de Pinochet, en ese tiempo". Según el senador

1 Senadora de la Unión Democrática Independiente, partido de derecha. 
...esas protestas fue [sic] de una masividad y de un impacto político tremendo, porque prácticamente todo el mundo pensaba de [sic] que el país ya estaba definitivamente sometido al régimen fascista. Y las protestas tuvieron un impacto tremendo. Y..., ¿̇se desplomó el Estado por eso? No se desplomó. Pensar que el Estado se va a caer es un diagnóstico completamente equivocado. ${ }^{2}$

Pero, ¿esas eran las aspiraciones del movimiento anti dictadura que tomó fuerza desde 1983? ¿Desplomar el Estado? ¿De dónde habrá tomado el señor Escalona tan arbitraria afirmación? Creemos que estas aseveraciones, más que tener un carácter histórico, sumamente documentando, provienen de una afirmación producto de una base ideológica y política que sustenta el régimen político desde 1973 hacia delante y que ha procurado marginar a los movimientos sociales y populares del ejercicio de la política, llevándolos solo al terreno electoral y reivindicativo como medios de expresión. A esto le hemos llamado "la privatización de la política" y es la base del discurso de ambos senadores ya señalados. Senadores que provienen de 'veredas políticas' supuestamente opuestas. Es por ello que las movilizaciones que se vivieron en Chile entre 1983-1987 son de vital importancia para graficar cómo los sectores populares, en un ambiente de absoluta adversidad, pudieron volver a actuar como sujetos políticos, irrumpiendo en el escenario nacional, negándose a esta privatización, rompiendo su monopolización por parte del Estado; pero no pudiendo construir un proyecto de carácter popular, quedando marginado de la mesa negociadora que la Concertación realizó con la dictadura militar desde 1989. El presente artículo busca resaltar el accionar de los sectores populares precisamente rememorando aquel periodo de protestas nacionales.

\section{Una historia desde los sujetos}

Intentaremos rescatar parte de dichas jornadas, pero desde el recuerdo de sus propios protagonistas. Es así que hemos tomado el camino de la historia oral, convencidos de que "la subjetividad forma parte de la historia" (Portelli, 1987, p. 35). Se cumplirán 39 años del golpe militar y la historia social todavía está en deuda con "los hombres y mujeres que protagonizaron [...] los

2 Entrevista a Camilo Escalona, más de 60 años, programa Mano a Mano por Alejandro Guiller (2011). 
conflictos del pasado", que generalmente han sido las elites, "las instituciones del Estado, los partidos políticos, las Fuerzas Armadas y sus diversos intelectuales y portavoces" (Garcés; Leiva, 2005, p. 13), como la Iglesia y su defensa a los Derechos Humanos. Hacer una historia de las 'protestas' ocurridas entre 1983 a 1987, desde sus propios protagonistas, es, a la vez, acusar y develar la privatización de la política y evidenciar cómo los sujetos populares, en diversos periodos, aunque adversos, han salido a la arena de lo 'político', ya sea en las fábricas, en las calles, en las universidades. Hemos elegido esta vez realizar este relato desde los recuerdos de militantes del MAPU - Lautaro (Acevedo, 2006) porque es una organización que nace en plena dictadura, se desarrolla en las protestas populares; pero ha sido estudiado parcial y arbitrariamente. ${ }^{3}$ Sobre este desconocimiento del propio MAPU-Lautaro (de aquí en adelante ML), Guillermo Ossandón, quien militó desde 1971 en el MAPU y fue uno de los fundadores del Movimiento Juvenil Lautaro, respondió por qué han sido considerados como un movimiento poco político o solitario:

El desconcierto pudo haber sido el origen: nacimos asaltando tiendas "Bata" con palos y cuchillos [...] Lautaro nació grande, capaz, con ganas, eso contribuyó al asombro [...] literalmente nos borraron de los registros de la izquierda. De otra parte, nosotros rápidamente nos enamoramos de la distancia, simplemente no éramos de ese mundo que ya empezaba a morir... Mi impresión es que, aparte de considerarnos bichos raros, no es mucho lo que saben de nosotros. (Richard, 2004, p. 66).

Por otro lado, el ML ha reflexionado desde su praxis sobre las protestas populares, planteando en los años noventa que con estas fue perdiendo el miedo a la dictadura, comenzando "el 'Corte Histórico'. La noche ya va quedando atrás. Con el 'Pueblo en Llamas' del 83 empieza a nacer el 'Movimiento Popular de la Victoria y el Poder"' (Partido MAPU, 1995, p. 7). Años antes, meses después de los primeros estallidos de las protestas nacionales, el ML planteó que el objetivo era luchar "por un Chile Popular [...] la expresión nacional del socialismo [siendo] el centro ordenador [...] la satisfacción plena de las necesidades del Pueblo. No nos satisface la mera noción de Normalización democrática" (Partido MAPU, 1983, p. 4). Con ello el ML, a diferencia de otras organizaciones contrarias a la dictadura, luchó contra

3 Nos referimos, sobre todo, al trabajo de Gaspar Domínguez y Paz Larraín (1996). 
esta; pero aspirando a una salida popular y no negociadora, de carácter socialista más que neoliberal. Dicha reflexión conecta la experiencia de la Unidad Popular y la transición hacia nuevas formas de hacer política que surgieron entre barricadas y movilizaciones.

Una de las dificultades a enfrentar para realizar este tipo de relatos es obtener los testimonios de quienes han realizado actividades ilegales y antidictadura, sobre todo después de que de dichos protagonistas hayan pasado muchos años sin hablar abiertamente por temor a la penalización judicial. Actualmente creemos que se ha abierto un proceso de reconstrucción de la memoria colectiva, donde los testimonios de quienes lucharon violentamente contra la dictadura militar moralmente han tenido mayor aceptación en la opinión pública, siendo menos condenados. Esto se ha producido principalmente por el reconocimiento de la violación de los Derechos Humanos de parte del Estado chileno, a pesar de la dificultad que se ha tenido para procesar a militares o civiles involucrados en estos hechos; además, la muerte de Pinochet el 2006 y el descubrimiento de su enriquecimiento ilegal han generado que la dictadura, al menos en el ámbito público, sea cada vez menos legitimada. Al contrario, las acciones en contra de la dictadura han sido más aceptadas, por lo que es mucho más posible hablar de las protestas y acciones clandestinas. Otro elemento es que los testimonios que aquí se darán fueron entrevistas realizadas en 2005, es decir, un año antes de la llamada "revolución pingüina" y seis años antes de las movilizaciones estudiantiles del 2011; por lo tanto, que no estaba la experiencia del retorno de las grandes movilizaciones; pero nos hemos dado cuenta que muchos de quienes entrevistamos ya el 2005 sentían un respeto y una valoración de su lucha en los años ochenta más allá de ese periodo. Actualmente muchos de los entrevistados que en este escrito expondremos han participado en las multitudinarias marchas o han apoyado a los estudiantes, ya sea como padres y apoderados o como trabajadores. La experiencia de los años ' 80 , de las protestas populares, se ha podido traspasar de alguna manera a las nuevas generaciones, que han salido a exigir no solo un cambio en la educación, sino un Chile distinto. Las aspiraciones del Chile Popular o la toma de lo cotidiano siguen vigentes en sus relatos. Actualmente toman mayor fuerza, ya que sus luchas pueden ser vinculadas nuevamente a las aspiraciones sociales. Joaquin, ${ }^{4}$ que fue dirigente del ML, rememora el 2005:

4 En adelante, todo nombre en cursiva corresponde al nombre político del entrevistado. 
Miles de personas que dejan el miedo atrás y, por lo tanto, se atreven a salir a la calle, frente a frente, a luchar contra el enemigo que tienen, que es la dictadura. Esos son elementos de victoria, afirmativo, y son elementos que marcan la historia del Pueblo. Por eso [es] que muchos, fundamentalmente los historiadores del sistema, han querido borrar este periodo. Nadie habla de las protestas, nadie habla [de] que existió un 'pueblo en llamas', nadie habla de que murieron decenas de jóvenes populares en las poblaciones, y, en ese periodo, la mayoría de los jóvenes son populares y nadie los recuerda. Se recuerda al Tucapel Jiménez, ${ }^{5}$ se recuerda a una estudiante universitaria por ahí, pero a las decenas de jóvenes populares que murieron en las poblaciones, que murieron en Ochagavía, ${ }^{6}$ nadie los recuerda. Estamos hablando de un periodo de un avance del movimiento popular [...] un pueblo en la calle, peleando contra la dictadura, peleando por sus necesidades. Y es eso es hoy día rescatable, hoy día cuando hay que empezar a crear fuerza popular, pa' luchar por las necesidades, cuando hay que salir a la calle $[. .$.$] hay que rescatar este periodo. { }^{7}$

Si debemos mencionar un comienzo, aunque sabemos que las causas de estos hechos no partieron en 1983, tendríamos que mencionar el 11 de mayo de 1983, que tras la convocatoria a paro por la Confederación de Trabajadores del Cobre, se transformaría en protesta nacional. Protesta que abrirá un nuevo escenario político en el país.

\section{Mayo de 1983, el otro 11}

Chile pertenece ya a una nueva realidad Juan Pablo Cárdenas (1983, p. 2).

11 de septiembre 1973 - 11 de mayo de 1983.... Diez años de distancia y la figura de Salvador Allende combatiendo en La Moneda vuelve a resurgir con su mensaje de que "más temprano que tarde se abrirán las grandes alamedas... y la historia la hacen los pueblos". Diez años y el miedo seguía presente

5 Líder sindical de la Democracia Cristiana asesinado en febrero de 1982 por agentes del Ejército.

6 Sector del sur de Santiago donde se dio una álgida movilización en contra de la dictadura.

7 Joaquin, más de 50 años, dirigente de MAPU-Lautaro, Santiago de Chile, 16 de febrero 2005. 
en la vida de miles de chilenos(-as). Una de ella era Marisa, quien, a pesar de la dictadura, siguió militando y participando en organizaciones sociales de las poblaciones José María Caro y luego en Dos de Marzo (actualmente, al sur de Santiago). Su vida, como la de muchos jóvenes populares, era una mezcla de miedo a la dictadura y de ganas de sacarla: no era solo un asunto político; era algo que tenía que ver con sus vidas cotidianas. Del 11 de septiembre de 1973 Marisa poco recuerda... Lloró mientras escuchaba por radio que la Moneda era bombardeada, y luego no se acuerda de nada hasta comienzos de octubre. Tiene más de 15 días borrados de su mente. Desde aquel 11 de septiembre fumará por más de 25 años.

Eso pa’ mi fue mortal y mi mamá me encerró y no me dejó salir. Porque yo quería salir a la universidad, a estar con mis compañeros, en realidad yo no tenía la magnitud, y nadie la tenía, de lo que significaba este golpe, excepto la gente que tenía una preparación más militar. Yo, más intuitiva, cachaba que era terrible. ${ }^{8}$

Pero el 11 de mayo del 83 -el otro once- fue muy distinto para Marisa. Todos esperaban que algo ocurriera aquella noche; pero pocos pudieron adivinar tamaño estallido social. El instructivo realizado por la Confederación de Trabajadores del Cobre (1983, p. 1) llamaba a realizar una movilización donde se llamaba a romper "con el temor, el inmovilismo y la indiferencia", por "libertad y democracia"; pero planteaba: "nuestra protesta será activa y pacífica”. El gobierno militar se preocupó; pero le bajó públicamente el perfil diciendo que no "debía ir más allá de un cierto grado de ausentismo escolar" (Geis, 1983, p. 4), advirtiendo: "Si se produce algún paro de actividades en el país, los responsables tendrán que atenerse a las consecuencias” (Si hay un paro..., 1983). El mensaje era claro: prisión, muerte, relegación y exilio. No obstante sus amenazas, la jornada terminó con una protesta nacional que reunió tanto a trabajadores (de bancos como del PEM), profesores y estudiantes de las universidades de Santiago, Valparaíso y Concepción, pobladores, sectores medios, presos políticos y público en general, dejando un saldo de 2 muertos, 50 heridos y 300 detenidos (Garcés; Maza, 1985, p. 29).

8 Marisa, más de 50 años, militante del MAPU-Lautaro, Santiago de Chile, 26 de Febrero de 2005. 
Aquel once, Marisa recuerda haber llegado de su trabajo cuando comenzó a escuchar los cacerolazos y las bombas: "yo me reía sola, porque no podía creer que había tanta gente en las calles o en sus casas tocando, a esta misma hora, metiendo tanta bulla, con esto de las ollas, después de tantos años de silencio [...] Era una bulla impresionante...." Guillermo, dirigente del MAPU en esa época, vivió el estallido en Santa Adriana. Allí llegaron las primeras informaciones de parte de militantes que recorrían todo el sector en bicicleta, “... y, de repente, un estallido, un corte de luz [...] y estaba la cagá en todos lados y las calles estaban llenas de gente, las protestas nacieron masivas [...] era como: 'chucha, por fin'. Esa noche se empezó a acabar la dictadura. Hasta ahí la dictadura mandaba". ${ }^{10}$ De alguna manera, con las protestas, quienes participaron en ellas y que tenían una actividad de resistencia a la dictadura, sienten que comenzó un nuevo momento en sus vidas y en el país. Fue una alegre sorpresa cómo la masividad de las protestas sobrepasó a las fuerzas políticas y les permitió desarrollar toda su política. Manolo, militante del MAPU en La Granja, recuerda que ese primer día

como partido no teníamos nada programado nada en la noche, nada. Pero, no sé por qué, preveíamos partido. La cosa es que ese día en la tarde, en forma espontánea, aquí nadie se puede arrogar que el producto de lo nuestro ocurrió. Fue absolutamente espontáneo. [...] La idea era hacer un cacerolazo: tocar las ollas. Pero resulta que, llegada la hora, empieza a salir la gente a la calle, con ollas, cacerolas, a tocar. Pero masivamente; no eran dos o tres en la esquina. Eran 20 y 30 y empiezan a hacerse barricadas y en todas las poblaciones. [...] Fue una lucha larga, larga. Me acuerdo que fue bastante prolongada, los pacos en las calles y nosotros, con lo que teníamos. ${ }^{11}$

Si bien hubo espontaneidad, con la segunda protesta, en junio de 1983, los sectores con más experiencia de organización política lograron crear diversas dinámicas para defender sus territorios, ya fuese en la autodefensa, como

9 Marisa, más de 50 años, militante del MAPU-Lautaro, Santiago de Chile, 26 de febrero de 2005.

10 Guillermo Ossandón, más de 50 años, dirigente de MAPU-Lautaro, Santiago de Chile, 8 de julio de 2005.

11 Manolo, más de 50 años, fundador del MAPU-Lautaro en comuna de La Granja, Santiago de Chile, 4 de Junio 2005. 
para resolver las necesidades cotidianas de cesantía y alimentación, dándose una cualificación de las jornadas a medida que pasaba el tiempo, sobre todo para proteger a las poblaciones de la represión policial, la cual se expresaba en heridos, detenidos y muertos; pero aquel 11 de mayo de 1983 fue de mucha alegría. Juan, también de La Granja, recuerda que

en la primera quedamos como, no como un plop, pero quedamos a la expectativa de lo que estaba pasando. Porque, en la primera protesta que se llevó, hubo dos poblaciones, que fue la Yungay y La Victoria, donde se produjo un levantamiento de masa. A lo cual esas dos poblaciones al otro día fueron represivamente allanadas. [...] Pero después, como en la segunda, la tercera empezamos a enganchar frente al tema, y empezaron aparecer otros sectores, apareció más propaganda de diferentes partidos. ${ }^{12}$

Es decir, si volvemos a las palabras del senador Escalona, efectivamente las protestas populares del ' 83 al ' 84 fueron absolutamente masivas y cambiaron al país. "Cuando comienza la primera protesta y de ahí pa' adelante el miedo se acabó. Por eso te digo que la dictadura empezó, a partir de ese momento, empezó a retroceder, pierde la iniciativa, pierde la ofensiva que hasta ese instante eran avasalladora", recuerda Guillermo. ${ }^{13} \mathrm{El}$ semanario de oposición llamado Análisis lo planteará de la siguiente manera:

El 11 de mayo de 1983 cambió el escenario político chileno. Un llamado de los dirigentes de la Confederación de Trabajadores del cobre a los chilenos, para que manifestaran abiertamente su protesta contra el sistema económico, político y social, se transformó en una inesperada jornada de protesta nacional. (Entrevistas escogidas, 1983, p. 5).

Pero en lo que no hubo acuerdo fue en los orígenes, en sus protagonistas y en los significados. De allí que buscaremos estas explicaciones, desde los testimonios de quienes participaron en ellas.

12 Juan, más de 40 años, militante de MAPU-Lautaro, Santiago de Chile, 19 de Marzo de 2005.

13 Guillermo Ossandón, más de 50 años, dirigente de MAPU-Lautaro, Santiago de Chile, 8 de julio de 2005. 


\section{Acerca de los orígenes de 'las protestas'}

Gran parte de los estudios realizados en la década de los '80 sobre los orígenes de las protestas populares han resaltado la crisis económica de 1982 como la causa principal de su estallido, como si fuera una mera ecuación "pobreza = protesta”, o como si la violencia surgiese solo de la frustración de los sectores marginales, por no estar integrados al Estado. Es el caso de Sofía Correa, que coloca la causa "económica” por sobre la "política”, planteando que, en 1982, "el PGB cayó en un 14,4\%" y "las cifras de cesantía, habiéndose registrado un 19,6\% en 1982". Para E. Valenzuela (1984, p. 8), la crisis no es solo económica sino que estructural, debido a los procesos de modernización del Estado, han dejado de cumplir un rol integrador, provocando "una crisis anómica, es decir, situaciones de desintegración y crisis de identidad cultural generalizadas". Desde el punto de vista de los sectores populares, la crisis económica se estaba resintiendo desde mediados de los 70, cuando se implementaron las primeras medidas neoliberales y se disminuyó el gasto fiscal. Mónica, quien después militará en el MAPU, recuerda su infancia en su población Dos de Marzo:

De lo que yo me acuerdo que la primera Pascua que nosotros pasamos en dictadura, nosotros no teníamos qué comer. Y una tía mató un pato, era más flaco el pato, tenía puro pellejo. Y ella se vino para acá, a la noche con nosotros y al pobre pato... - "Lo hicieron mierda" [comenta su hermano Eric]-, Pero así con mucha pena, yo me imaginaba esa película de Walt Disney, donde el pato está pasando hambre, donde tenían un queso todo transparente. Un pato flaquísimo, que tenía un poco de arroz. Y lo comimos así. Y mi mamá y mi tía lloraban comiéndose al pato flaco, porque estaba más flaco que..., los siguientes años eran malos, yo me acuerdo que mi mamá no tenía plata ni siquiera pa’ comprar pan. Porque mi mamá hacía pan en un tarro. Ella amasaba y hacía pan en un tarro cuadrado... ${ }^{14}$

Paralelo a esto se formaron grupos en las iglesias, que, además de hacer trabajo parroquial, desarrollaron un trabajo social y político con cientos de jóvenes. Mane es una de ellas, que, con 11 años, ingresó a una parroquia en la comuna de La Granja. Su madre quería que hiciera la primera comunión:

14 Mónica, más de 40 años, militante de MAPU-Lautaro en los ochenta, Santiago de Chile, 22 de Mayo de 2005. 
...Los domingos iban jóvenes que tocaban guitarra en la misa misma y después se quedaban a conversar, entonces pa nosotros fue abrir el círculo de amigos. En verdad en la cuadra no teníamos muchos amigos, solamente los de al lado, y, cuando mis papás se enojaban por esa cosa de los comunistas, nos separábamos; pero nosotros a escondidas nos veíamos. Entonces no teníamos acceso a amigos; porque mis viejos, además, no nos dejaban salir a la calle. Éramos, aquí adentro, no más nosotros. Entonces el hecho de ir pa' allá a la capilla dos veces a la semana, más el domingo, fue creando vínculos con esos jóvenes que eran mayores que nosotros. Ellos ya tenían 18 o 20 años, y nosotros teníamos unos 15 años. [...] Se hablaba era de hacer actividades, de ayudar a la gente, de hacer el puerta a puerta cuando había lluvia y después también el cura que hablaba otros temas. Pedía por los desaparecidos, por los cesantes, de hacer ollas comunes [...] después me acuerdo que nos invitaron a participar en los grupos juveniles. ${ }^{15}$

Son esos centros juveniles, que se desarrollaron hasta convertirse en organizaciones, los que dieron sustento a las protestas que vendrían desde 1983. Muchos jóvenes se dieron cuenta, además, de los llamados Comités de Resistencia, los cuales eran pequeñas células que realizaban territorialmente actividades de propaganda en contra del régimen militar. Alfredo recuerda que

eran caminatas larguísimas, llegábamos cansados, traspirados y una cantidad inmensa de panfletos que se regaban por todas partes [...] yo salía consciente, decidido, incluso con alegría salía a participar en la propaganda. También con miedo, porque el momento que vivíamos: o nos íbamos presos o nos iban a agarrar a balazos, o teníamos que salir arrancando, o teníamos que meternos a cualquier casa a escondernos, o tirarnos de guata al suelo por ahí. ${ }^{16}$

Se realizaron encuentros y coordinaciones entre diversos centros juveniles, como el creado por el MAPU en la zona sur, llamado "Coordinadora Santa Rosa”. Juan participó en aquella experiencia:

15 Mane, más de 40 años, militante del MAPU-Lautaro desde su fundación, Santiago de Chile, 2 de Febrero de 2005.

16 Alfredo, más de 50 años, dirigente de MAPU-Lautaro, Santiago de Chile, 11 de Agosto de 2005. 
[...] nosotros vivíamos como un socialismo pequeño, que teníamos en Granja, porque te relacionabas con el otro ahí participabas, comías con el otro, salíai. Entonces era toda una cuestión de mi vida cotidiana que la dejé en la cuadra... era otro mundo. Salíamos a jornadas. Entonces tu vida giraba en torno a lo que era el movimiento de la Coordinadora Santa Rosa, y los grupos, y todo el mundo que te rodeaba, te saludaba, compartía, hacías cosas. Pa' mi suponte en la casa me desaparecí. Yo llegaba en las noches. [...] Pero la Coordinadora, yo creo que cuando se forma, logra evolucionar. ${ }^{17}$

Joaquin, dirigente del MAPU, recuerda que, además, hacían mítines relámpago:

Llevábamos un cajoncito, y empezábamos a aplaudir y un compañero (que previamente habíamos acordado) empezaba a pegar una arenga política contra la dictadura, llamando a resistir, llamando a salir a la calle. Principalmente dos eran los contenidos [...] Uno era "rompamos el miedo" y otro "salir a la calle". ${ }^{18}$

Es decir, independiente que no todo el país estuviera en organizaciones sociales, no se puede afirmar que las protestas fueron absolutamente espontáneas o meramente económicas. Joaquín afirma: "Decir que las protestas partieron solamente por la crisis económica de los ' 80 , donde quiebra la banca y la cesantía llega a niveles gigantescos, pa' mí, es una visión mezquina y economicista, porque desde el 78 se está creando un movimiento contra la dictadura que va sumando". ${ }^{19}$ Pero muchos cientistas sociales, en ese momento, no quisieron reafirmar que se podía construir un movimiento popular que instalará un nuevo proceso socialista. Para Eugenio Tironi, quien fue dirigente del MAPU hasta 1981, la protesta no será provocada por un 'movimiento de pobladores', sino que se entiende por un proceso de desintegración social, que es "el sentimiento de exclusión [...] la ausencia de un orden social donde poder participar legítimamente”. En realidad, existía, un "movimiento de militantes" de partidos políticos y no un "movimiento social". Más bien hay "un 'antimovimiento social', cuya expresión más patente es la violencia"

17 Juan, más de 40 años, militante de MAPU-Lautaro, Santiago de Chile, 19 de Marzo de 2005.

18 Joaquín, más de 50 años, Santiago de Chile, 16 de febrero y 9 de Julio de 2005.

19 Joaquin, más de 50 años, Santiago de Chile, 16 de febrero y 9 de Julio de 2005. 
(Tironi, 1986, p. 25-31). Esa es la razón del por qué finalmente "la protesta se aisló, incluso dentro de la población", ya que "se fue quedando en manos del activo político y de ciertos segmentos jóvenes radicalizados" (Campero, 1987, p. 31). Creemos que estas conclusiones finalmente legitimaron la visión de la Alianza Democrática (coalición formada por el Partido Democracia Cristiana y otros sectores socialistas que formarían en 1987 la Concertación por la Democracia). Según estos análisis, no viendo un movimiento social, sólo quedaba nuevamente mirar hacia el Estado y solucionar el destino de la patria a través de las estructuras tradicionales. Comienza a legitimarse la 'privatización de la política’ como fórmula para pactar la salida de la dictadura.

\section{El pueblo y los jóvenes como motor de las protestas}

Si revisamos la mayoría de la prensa opositora y los estudios sociales sobre los las movilizaciones de los años 80 en Chile, podemos consensuar que estas reunieron una serie de actores sociales y políticos, pero que muchas veces no le dieron el primordial a la juventud popular, la cual creemos que resaltó por sobre el resto de los opositores de la dictadura. A modo de ejemplo podemos mencionar el balance de las 21 personas más importantes del año que realizó a fines de 1983 la revista Análisis. Ocho personas fueron políticos-partidistas; cuatro, dirigentes sindicales; dos, académicos; una, periodista; una, religiosa, Raúl Silva Henríquez (Cardenal de Chile). Solo uno era dirigente poblacional (Eduardo Valenzuela, Presidente de la Coordinadora Metropolitana de Pobladores). Ningún joven (Monckeberg, 1983). Luego en 1987, la misma revista editó su libro "Entrevistas Escogidas". Eran 75 entrevistas a dirigentes políticos y sindicales, además de otras personalidades de la centro derecha incluso. De estas 75 entrevistas, 29 eran miembros de partidos políticos de oposición; 13 , profesionales; 6 , sindicalistas o trabajadores; 6, políticos de derecha; 2, de instituciones de Derechos Humanos; 6, representantes de la Iglesia; 2, personeros de Estados Unidos; 2, del mundo de la cultura; 5, miembros de las Fuerzas Armadas; 2, del mundo estudiantil; la viuda de Allende y un poblador, el mismo Eduardo Valenzuela. La propia revista se hace una autocrítica: "Quizás hay una insuficiencia de entrevistados de las organizaciones sociales, y tal vez la muestra es extremadamente santiaguina para representar al país. Asumimos esas carencias en el entendido que ella reflejaron un trabajo periodístico que está inconcluso..." (Entrevistas 
escogidas, 1983, p. 6). Inconcluso o no, esta es una muestra de lo diverso que era el movimiento de oposición; pero también de la notoriedad e importancia que se les daba a las organizaciones juveniles y poblacionales en la prensa de oposición. Sobre lo mismo, a Rodolfo Seguel Presidente de Confederación de Trabajadores del Cobre, se le preguntó en mayo de 1983:

\section{¿Parece que le impresionó mucho que el llamado de los trabajadores del cobre tuviera tanto eco en los jóvenes. - Sí. No pensaba que iba a ser tan grande la respuesta. Creía, erróneamente, que la juventud chilena está quizá más apagada y un poco más al margen de lo que estaba ocurriendo realmente en el país. Pero con esto me doy cuenta de que están al tanto de todo lo que ocurre y quieren expresar su palabra de protesta por la realidad que vivimos. (Entrevistas escogidas, 1983, p. 11-12).}

Pero lo que apareció como algo minimizado desde las revistas de oposición, en los testimonios de los mapucistas que crean el Movimiento Juvenil Lautaro, se percibe una visión distinta. Serían los jóvenes populares los que tuviesen mayor participación en las jornadas de protestas: "Por eso nace el Lautaro. Nosotros hubiéramos podido crear el Lautaro el 78. No nos pesca nadie. Ahí hay una generación. Y esa generación la hegemonía la tiene la juventud popular, no la juventud estudiantil". ${ }^{20}$ En documentos del ML se reafirma lo siguiente: "La juventud popular es ya en todo el país un sujeto protagónico en la movilización contra la dictadura” (Partido MAPU, 1983, p. 14). La lucha era por "un país para el pueblo", que "solo lo hará realidad el pueblo mismo" (Fuera Pinochet..., 1985). Pueblo y juventud. Esto se contrarresta con la visión hegemónica que existía hasta la Unidad Popular en el movimiento popular, en donde los sujetos sociales como los campesinos, pobladores y estudiantes eran complementarios al proyecto de cambios que lideraba la clase trabajadora. Para Luciano, "el MAPU nunca dio por cerrado el sujeto de la Revolución, nunca dijo: el sujeto de la revolución es la clase obrera. O capaz que lo haya dicho y yo nunca supe. Eso da una posibilidad, de que el sujeto de la revolución siente se está construyendo". ${ }^{21}$ Gonzalo, joven de 15 años en tiempos de las protestas, cuenta su experiencia en el MAPU:

20 Joaquin y Nico, ambos más de 50 años, fundadores de MAPU-Lautaro, Santiago de Chile, 10 Octubre de 2011.

21 Luciano, más de 50 años, militante del MAPU-Lautaro, Santiago de Chile, 21 de Junio de 2005. 
Yo creo que en un momento determinado el movimiento poblacional se planteó como el eje, en los primeros instantes de constitución, de construcción de alternativa. Posteriormente, ya cuando existe la separación entre el MAPU-Lautaro y el MAPU pitufo [liderados por Víctor Barrueto], ya empieza a trabajar de manera más dirigida hacia lo que era la juventud popular, juventud más rebelde, y ahí empieza a plantearse la juventud como el motor de la revolución con el eje central. Ahí se instala. Para nosotros, evidentemente, se construía un grado de referencia como el partido, como un conductor, como el intelectual orgánico, vinculante a todo lo que era la estructura más política, el Movimiento Lautaro como la vinculación entre los sectores avanzados y el partidos, y los sectores avanzados y el conjunto de Pueblo, como una cosa media [sic] concéntrica. ${ }^{22}$

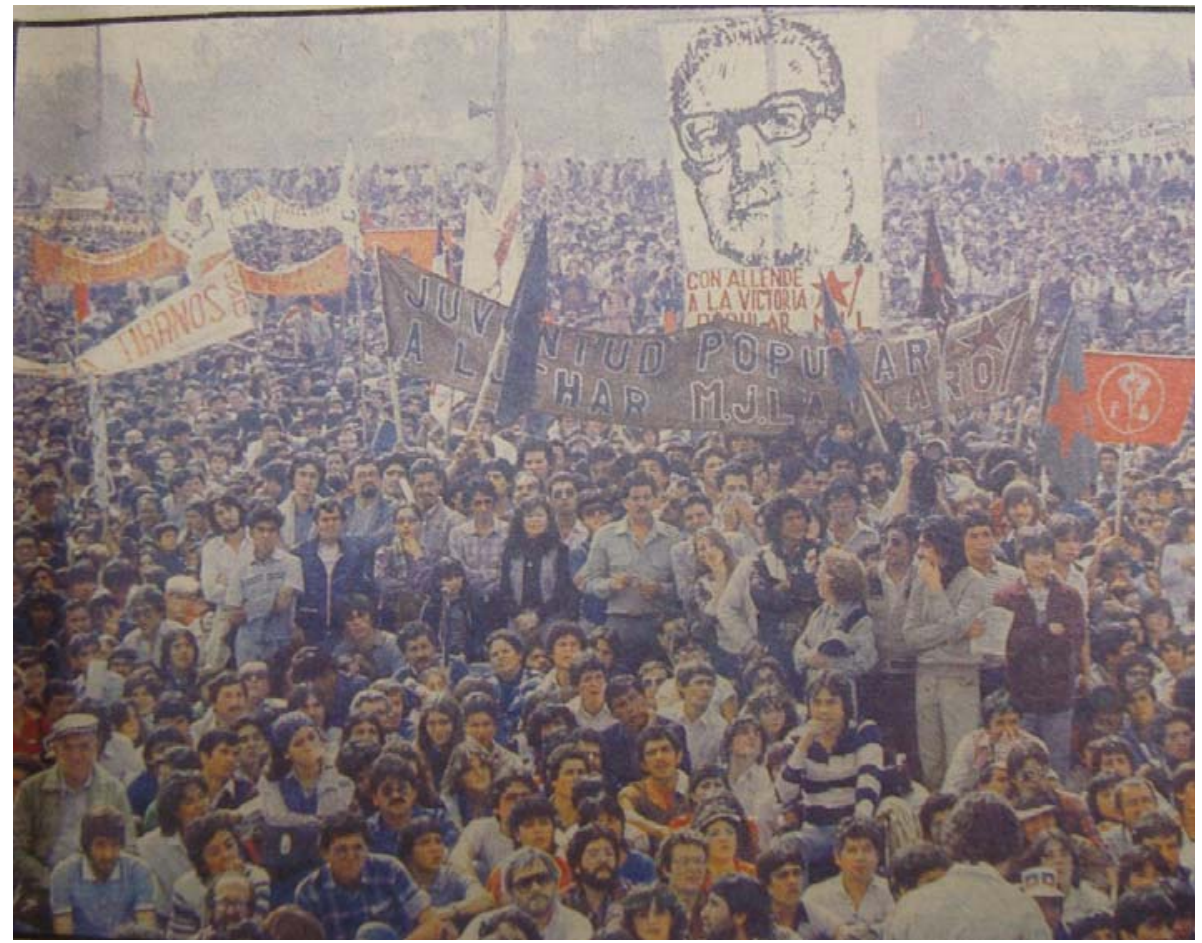

Brigadistas del Movimiento Juvenil Lautaro en concentración contra Pinochet, 1 de mayo de 1984.

22 Gonzalo, más de 40 años, militante del MAPU-Lautaro, Santiago de Chile, 12 de Septiembre de 2005. 


\section{Significados e importancia de recordar las protestas populares}

Las jornadas de protestas, su preparación y ejecución, fueron, para los militantes del MAPU-Lautaro, un espacio-tiempo de mucha creación, libertad y recuperación de la política, al sentirse nuevamente protagonistas de la historia del país y poder ejercer el poder y la participación desde los propios territorios. Pero, a la vez, fue un tiempo- espacio de mucho desgaste, de mucho apuro, donde los protagonistas sienten que no pudieron asimilar totalmente todos los aprendizajes que la misma práctica les fue entregando. Hemos querido ordenar los testimonios de sus militantes en una serie de factores sobre las lecciones de las protestas y las temáticas que están relacionadas con el presente.

El ejercicio de la politica desde los territorios: Primeramente, plantear que desde los años 70 y 80 el ejercicio de la política está transitando desde los espacios más institucionales, como sindicatos y parlamento, a otros espacios, como la participación en espacios barriales, escolares, universitarios, en organizaciones que se relacionan con el Estado; pero teniendo una mayor autonomía frente a estos. Insistimos que estos son procesos de larga duración, que si bien el golpe de Estado de 1973 los obstaculizó, no pudo anularlos completamente en los sectores populares y con las protestas se siguieron potenciando. Los militantes del ML, cuando recuerdan las protestas, plantean que el beneficio de venir de los mismos territorios no fue solo el sentirse más en confianza, sino que generaban relaciones comunitarias que ayudaban a su política. Mane recuerda que en las protestas vieron "esa posibilidad de hacer de hacer cosas, porque igual después, en el tiempo de las protestas y antes, rayamos, igual con más claridad, la gente nos cachaba un poco más, no teníamos ese miedo que la gente nos cachara y dijera: 'estos son de Lautaro y andan rayando', íbamos pa' que nos vieran”. ${ }^{23}$ Gonzalo cuenta que:

...Salíamos temprano a hueviar a las protestas, a hacer las barricadas y tipo una de la tarde íbamos a la olla común... almorzábamos con las viejas, ellas nos cuidaban, reposábamos un rato y como cuatro de la tarde empezábamos

23 Mane, más de 40 años, militante del MAPU-Lautaro desde su fundación, Santiago de Chile, 2 de Febrero de 2005. 
a movernos... empezaban a operar lo que eran los comités de salud... donde nosotros sabíamos que teníamos que llegar si andábamos con problemas de repre, de heridos y con gente. ${ }^{24}$

Existían el ejercicio del poder y el control geográfico que, aunque era por periodos cortos, iban dejando huellas en la memoria de quienes los vivieron. Jorge recuerda que en una oportunidad en Valparaíso:

Los pacos se escondieron donde los bomberos, los gallos asustados. Primera vez que ven una turba tan grande y seguramente no estaban preparados para enfrentar esta cuestión y la gente feliz, ver unas tres o cuatro horas de marcha, cotota... propaganda, gritos, todo ese tipo de cosas. La gente feliz, era una catarsis, la gente contenta, se abrazaba, cotota, era en otra, ahí salió todo el mundo. ${ }^{25}$

Dicha lucha en territorios estaba mucho más cercana de las reales necesidades que los sectores populares requerían.

Lucha por necesidades subjetivas y objetivas. Se podría pensar que la lucha subversiva y los métodos violentos en los sectores populares fueron ocupados en los ' 80 debido al cierre de otros espacios institucionales producto de la propia dictadura militar; pero hay que recordar que, desde los años 60, se fue masificando la "toma" como método de avance y de ejercicio de hacer política desde el movimiento popular, que no era contradictorio con métodos electorales. Es así como nacieron decenas de poblaciones, o se generaron reformas universitarias o muchas comunidades indígenas recuperaron sus predios y aceleraron la reforma agraria. En los ochenta las necesidades que fueron “tomadas" por los sectores populares y organizaciones que desde allí se generaron no fueron solo objetivas sino que subjetivas. El ML planteaba, como pueblo, en 1985: "[Debemos] desarrollar nuestras capacidades artísticas y culturales, derecho a la recreación de nuestras familias. Queremos libertad y justicia, nunca más dictadura militar" (Partido MAPU, 1985, p. 1). Esto derivó que, desde 1987, comenzará a plantear la importancia de las necesidades como la felicidad. Bernardo afirma:

24 Gonzalo, más de 40 años, militante del MAPU-Lautaro, Santiago de Chile, 12 de Septiembre de 2005.

25 Jorge, más de 40 años, dirigente de MAPU-Lautaro, Santiago de Chile, 16 de Junio de 2005. 
Nosotros planteamos el problema del sexo nuestro y la felicidad plena, es decir, el derecho de la juventud a ser feliz y sin que corra riesgos. Por lo tanto, planteamos una política que era de recuperación de condones y de repartirlos; entonces los repartíamos en todos lados: en el Peda. Ahora, esa expresión política, obviamente, fue mal mirada por la izquierda, por el mismo Frente, por el MIR, que no la entendía. ${ }^{26}$

Pero las necesidades en los años ' 80 fueron necesidades que se tomaron, por una parte de la población, precisamente porque no había suficientes canales de parte del Estado. A partir de los gobiernos de la Concertación, el discurso fue comenzar a utilizar los mecanismos de participación implementados por la elite política, como fueron la generación de proyectos concursables. Los tiempos de lucha armada y la violencia política, al parecer, se fueron acabando. Pero, con el tiempo, los nuevos movimientos sociales que han venido surgiendo en el país no se plantean ni pacíficos, ni armados, utilizando los medios de presión e ilegales cuando es necesario; pero, también, sin negarse al dialogo, a las asambleas y a un proceso de democracia más horizontal. Creemos que este proceso viene, precisamente, de la experiencia de los ' 80 y de las barricadas, ya que el pueblo tiene una memoria de que, en un momento dado, salió a las calles y se dio una batalla callejera nunca antes vista en los territorios populares. Gonzalo se refiere a cuando más de 300 personas atacaron la comisaría de Carabineros de su población, Santa Adriana:

Me acuerdo de otra protesta en que yo no sé cómo empezó... Estaba todo Callejón Lo Ovalle lleno de barricadas, eran temprano, como las tres de la tarde, sino antes... Y desde ahí le tiraban peñascazos a los pacos. Nosotros, por delante también, desde las esquinas, de los pasajes, tirándole capotazos... los pacos estaban parapetados adentro en un muro que tenía... Fue tanto el hueveo que, había un compa que como a diez metros estaba sentado, frente a la comisaría, con un pañuelo en la cara... sentado. Los pacos no le dispararon, ni una bueá... Estaban esperando a que llegaran los refuerzos. ${ }^{27}$

26 Bernardo, más de 50 años, dirigente del MAPU-Lautaro, Santiago de Chile, Julio de 2007, entrevistado por Héctor Ordenes.

27 Gonzalo, más de 40 años, militante del MAPU-Lautaro, Santiago de Chile, 12 de Septiembre de 2005. 
De alguna manera, nuestros entrevistados sienten que, en las protestas, miles de chilenos no tuvieron problemas en utilizar la violencia; pero que efectivamente faltó tiempo para generar un proyecto popular autónomo. Mane piensa que en esa época era vivir en función de la protesta"; pero se pudo "haber organizado mejor las cosas, haber conversado más cosas, porque al final fue como puro movimiento... porque lo que veis tu, al final, quien sacó beneficio de todo esto fue la Democracia Cristiana, o todo el grupo de la Convergencia, porque todo lo que se provocó fue producto de la gente de las poblaciones. ${ }^{28}$ Emilia siente que en ese tiempo se tenía conciencia de que se quería derrocar la dictadura, pero "nosotros queríamos algo distinto y queríamos manifestarlo, no queremos dictadura, no queremos milicos, queremos un gobierno... Construir una patria más justa y popular, como decíamos nosotros. Pero había gente que quería solo cambiar de gobierno.". Guillermo plantea:

Lo que faltó ahí fue crear una fuerza popular", y eso nos quedó a todos grande, por supuesto a Lautaro incluido... Y en el tiempo de las protestas hubo mucha gente, muchísima gente, que estuvo dispuesta a darlo todo, por la victoria revolucionaria... Todo, todo, todo... Y no hubo capacidad de canalizarla, toda esa tremenda energía. Y después se empezó a diluir el movimiento masivo, quedamos los grupos militantes, las brigadas y nosotros tratamos de provocar el reventón con nuestra experiencia de guerra y terminamos haciendo la guerra solos, eso fue. $Y$ después finalmente terminamos en cana. ${ }^{30}$

Para el que fue el Secretario General del MAPU - Lautaro, las protestas generaron un puente entre la experiencia de la Unidad Popular y la actualidad. En muchos de nuestros entrevistados, el recordar las protestas ha significado una proyección de nuevas luchas y posibilidades de que el sujeto popular pueda generar un proyecto de cambio social. Juan plantea que las protestas significan:

28 Mane, más de 40 años, militante del MAPU-Lautaro desde su fundación, Santiago de Chile, 2 de Febrero de 2005.

29 Emilia, más de 40 años, militante y dirigente intermedio de MAPU-Lautaro, Santiago de Chile, 2 de Abril de 2005.

30 Guillermo Ossandón, más de 50 años, dirigente de MAPU-Lautaro, Santiago de Chile, 13 de julio de 2005. 
Un ejemplo que puedo sacar es que si podimos [sic]... que podemos llegar a esa altura. Que podemos llegar y podemos lograr a lo que nosotros pensamos, una insurrección de masas, a una lucha masiva, que podemos cambiar esta forma de ser que nos tiene, porque ya vivimos y ha habido una historia y esa historia te marca que si es posible, de que si es posible de crear otro Chile que si es posible que esta gente despierte, que esta gente se vuelva a unir. $^{31}$

Valentina, que nació en la zona sur de Santiago (Ochagavía) y, que participará en centros juveniles, reflexiona:

Obviamente, debilidades hubieron [sic] muchas. De repente, quizás en la misma organización empezó a caer la gente, los muerto [sic], los presos, no sé que... quizás no tuvimos tanta fuerza, a lo mejor, debimos habernos quedado, quizás si nos hubiésemos apoyado más en las organizaciones, o no sé, no sé qué evaluación, qué difícil pregunta... Yo creo que el hecho de poder salir, de atreverse a tomarse los espacios, a salir, que la gente, y a reconocerse porque al final, salía uno: "ahh, chuta, este también era de izquierda o este gallo también, o no es de izquierda, pero está en contra este sistema”. Cachai, entonces atreverse a salir y empezar a reconocerse con otra gente que también estaba pensando igual. Eso fue como lo fuerte ahí con las protestas. ${ }^{32}$

\section{Luciano siente que fueron}

los momentos de irrupción masiva los que ponen a la orden del día la revolución, y esos se dan tarde, mal y nunca. Entonces, como se dan tarde, mal y nunca, cuando se dan hay que cachar muy bien donde le achuntamos y donde no le achuntamos, porque van a volver a aparecer esos momentos y tenemos que hacerlo mejor que el día anterior, porque en una de esas le vamos a pegar al bueno. ${ }^{33}$

31 Juan, más de 40 años, militante de MAPU-Lautaro, Santiago de Chile, 19 de Marzo de 2005.

32 Valentina, más de 40 años, militante del MAPU-Lautaro, Santiago de Chile, 7 de Mayo de 2005.

33 Luciano, más de 50 años, militante del MAPU-Lautaro, Santiago de Chile, 21 de Junio de 2005. 
Muchos de nuestros entrevistados han estado ligados a las movilizaciones actuales, en su mayoría, ya que sus hijos han sido participes de las tomas y organizaciones estudiantiles existiendo una transmisión histórica de conocimientos e ideas de generación en generación.

\section{Conclusiones}

Chile se enfrenta a una doble transición hacia la democracia (que, a la vez, son dos tipos de democracia: representativa neoliberal / participativa popular). Por un lado, la clase política y empresarial que ha gobernado en Chile desde 1973 hasta la actualidad, ha seguido el camino marcado por la dictadura de Pinochet desde el discurso de Chacarillas en 1977. Allí, celebrando el día de la juventud, Pinochet les plantea a una serie de jóvenes (muchos de los cuales, en la actualidad, pertenecen al gobierno de Sebastián Piñera, como los ministros Andrés Chadwick, Joaquín Lavín y Pablo Longueira), los pasos hacia la nueva "nueva institucionalidad": Primero, la recuperación de la democracia que, según su análisis, se pudo realizar mediante el golpe de las Fuerzas Armadas en 1973. Luego, un proceso de transición (integrando a civiles al gobierno con una nueva constitución, que sería aprobada en dudosas elecciones en 1980) y, finalmente, el proceso de consolidación (Discurso del General Augusto Pinochet..., 1977). Con el triunfo del NO en 1988 y las elecciones de 1989, la Concertación resultó el conglomerado político triunfante, teniéndose que adecuar al modelo económico neoliberal heredado y a la Constitución de 1980, en parte producto del miedo a las Fuerzas Armadas y en parte por una opción voluntaria de convencimiento (Otano, 1995). Entre 1989 y 2003, la clase política realizó una serie de modificaciones a la Constitución, que no alteraron lo esencial del modelo y la democracia representativa (Cavallo, 2012). Un presidente tras otro plantearon el fin de la transición, no llegando hasta ahora a un consenso. Pero ¿estamos en la consolidación de la democracia? Si pensamos en el modelo creado por la Constitución, en una democracia restrictiva, claramente nos encontramos en dicha etapa. Patricio Aylwin (Presidente de Chile entre 1990-1994), cree que "es una estupidez hablar de transición a la democracia en este país, con perdón de la frase. Es una democracia. No es perfecta, de acuerdo. Pero una democracia siempre debe ir perfeccionándose, de acuerdo a las circunstancias" (Mendoza, 2011). Pero, una y otra vez, la ciudadanía se 
ha movilizado en los últimos años. No solo por necesidades objetivas, sino, además, por una democracia más participativa, sin el sistema binominal, y por una Nueva Constitución. Algunas cifras plantean que un $58 \%$ de la ciudadanía no se siente representada por ningún partido político (promedio desde 2008-2012); un 53\% cree que nuestra democracia funciona regular (promedio 2006-2012); mientras que, en agosto de 2012, un 49\% cree que el sistema binominal debería cambiarse (Centro de Estudios Públicos, 2012). Dichos movimientos sociales toman el proyecto histórico, con modificaciones claras, de un movimiento popular anterior que desde los años sesenta y setenta fueron construyendo una democracia popular y más participativa. Con el golpe, esta construcción quedó aparentemente detenida; pero las protestas populares demostraron que los sectores populares podían seguir soñando una democracia distinta (Garretón, 1987). Estas experiencias se han basado en nuevas formas de hacer política, desde lo territorial, por necesidades subjetivas, con mayor participación de las mujeres y los jóvenes, fuera del Estado. Muchas de estas formas se fortalecieron en las protestas aunque en los primeros años de la Concertación se agotasen. Dicha transición hacia una nueva democracia (popular y participativa) a diferencia de la "representativa", no está consolidada, sino que se encuentra aún en evolución. Difícilmente se logrará consolidar a través del modelo institucional, el cual, como planteamos al comienzo, se encuentra a la defensiva y continúa generado la "privatización de la política” a los sectores populares, precisamente por el miedo hacia la democracia más popular y participativa. Las protestas populares, más que un movimiento nuevo, como quizás creyeron los propios militantes del MAPU-Lautaro, han sido una continuación con nuevos aspectos e ideales de esta "transición hacia una democracia popular", han sido un puente político entre la experiencia del movimiento pre golpe y lo que hoy se está viviendo. De allí la importancia de la generación de Historia Reciente y la construcción de texto que ayuden a las memorias colectivas para que, los movimientos sociales han continuado. Guillermo Ossandón, que fue uno de los dirigentes del MAPU-Lautaro, planteó esta idea de "puente histórico", ligando las protestas con el pasado reciente y la actualidad:

Del puente entre lo que queda cortado con el golpe y que después se retoma con la idea del Corte Histórico y las protestas. Y el rol histórico de Lautaro, nosotros lo vemos, esencialmente en el dibujo de ese puente, fuimos los que estuvimos más cerca o avanzamos más en el diseño de ese puente, que 
permite dar una continuidad, con sus rupturas evidentes, a la historia. Y yo creo, hasta el día de hoy, yo estoy convencido de que eso es lo principal de lo que hemos hecho. El resultado de todo un camino a la fecha ya tiene que ver con ese puente. Nosotros hicimos ese puente con la guerra, lo terminamos con la guerra”.

Al referirse a la guerra, se refiere al enfrentamiento que el MAPU-Lautaro realizará luego de instalada la Concertación en 1990, donde esta organización continuó realizando acciones armadas y que terminaron con la mayoría de ellos en la cárcel hasta el 2005.

Y la guerra terminó como terminó, pero más allá de eso, lo importante es que efectivamente el puente existe. Entonces lograr darle un sentido a eso es una obra gigantesca y nosotros estamos orgullosos de haberla hecho, esa hueá tiene una importancia muy alta y fuimos los que la hicimos, pero esa fue una conceptualización que hicimos después, al final de la cárcel. ${ }^{34}$

La discusión sobre el tipo de democracia que se necesita en el país aun seguirá pendiente. Y esa una gran oportunidad para los movimientos sociales.

\section{Referencias}

ACEVEDO, N. Fuera Pinochet, Chile Popular! El MAPU-Lautaro en las protestas populares (1978- 1985). Tesis (Licenciado en Historia y Ciencias Sociales)-Universidad ARCIS, Santiago de Chile, 2006. Disponible en: <http://www.archivochile.com/tesis/04_ tp/04tp0017.pdf >. Acceso en: 20 sept. 2012.

CAMILA VALLEJO LLAMA a un "cacerolazo contra la represión". Radio Universidad de Chile: Diario Electrónico, 4 ago. 2011. Disponible en: <http://radio.uchile.cl/ noticias/117231/>. Acceso en: 5 ago. 2011.

CAMPERO, G. Organizaciones de pobladores bajo el régimen militar. Proposiciones, v. 14, p. 85-93, ago. 1987.

CÁRDENAS, J. P. Protesta nacional. Análisis, n. 58, p. 2-3, jun. 1983.

34 Entrevista a Guillermo Ossandón, 13 de Julio de 2005. Guillermo muere de cáncer en 2009. 
CAVALLO, A. Historia oculta de la transición: memoria de una época 1990-1998. Santiago de Chile: Uqbar, 2012.

CENTRO DE ESTUDIOS PÚBLICOS. Estudio nacional de opinión julio-agosto 2012.21 ago. 2012. Disponible en: <http://www.cepchile.cl/dms/lang_1/doc_5110.html>. Acceso en: 22 ago. 2012.

CONFEDERACIÓN DE TRABAJADORES DEL COBRE. Instructivo $n^{\circ}$ 2. Santiago de Chile, 5 mayo 1983.

DISCURSO DEL GENERAL AUGUSTO PINOCHET en Cerro Chacarillas con ocasión del día de la juventud, el 9 de julio de 1977. Archivo Chile. Disponible en: $<$ http:// www.archivochile.com/Dictadura_militar/doc_jm_gob_pino8/DMdocjm0003.pdf > . Acceso en: 20 sept. 2012.

DOMÍNGUEZ, G.; LARRAÍN, P.ElMAPU-Lautaro: los hijos descarriados de la izquierda. Tesis (Licenciatura de Periodismo)-Escuela de Periodismo, Facultad de Comunicación, Universidad Diego Portales, Santiago de Chile, 1996.

ENA VON BAER PIDE a la clase política el liderazgo para solucionar el conflicto estudiantil. El Mercurio On Line, 30 oct. 2011. Disponible en: <http://www.emol.com/ noticias/nacional/2011/10/30/510520/ena-von-baer-pide-a-la-clase-politica-que-asumael-liderazgo-para-solucionar-el-conflicto-estudiantil.html>. Acceso en: 31 oct. 2011.

ENTREVISTAS ESCOGIDAS: 75 personas conversan con Análisis. Santiago de Chile: Editorial Emisión, 1983.

FUERA PINOCHET, Chile Popular. El Pueblo Rebelde Vencerá, Santiago de Chile, n. 3, p. 1 , abr. 1985 .

GARCÉS, M.; LEIVA, S. El golpe en la legua: los caminos de la historia y la memoria, Santiago de Chile: Editorial LOM, 2005.

GARCÉS, M.; MAZA, G. de la. La explosión de las mayorias: protesta nacional 1983-1984. Santiago de Chile: Eco, 1985.

GARRETÓN, M. A. Las complejidades de la transición invisible: movilizaciones populares y régimen militar en Chile. Santiago de Chile: FLACSO, 1987 (Documento de trabajo n. 334).

GEIS, I. ¿Fútbol o ajedrez? Análisis, n. 58, p. 4-7, jun. 1983. 
GUILLER, A. Camilo Escalona: Ministro Bulnes no quiso negociar con estudiantes. 24 Horas, 1 dic. 2011. Disponible en: <http://www.24horas.cl/programas/manoamano/ camilo-escalona-ministro-bulnes-no-quiso-negociar-con-estudiantes-44067>. Acceso en: 2 dic. 2011.

MENDOZA, M. Todos confesos. Santiago de Chile: Mandragona, 2011.

MONCKEBERG, M. O. Los 21 del año. Análisis, n. 70, p. 4-9, 6-20 dic. 1983.

OTANO, R. Crónicas de la transición. Santiago de chile: Editorial Planeta, 1995.

PARTIDO MAPU. Resoluciones politicas del Quinto Pleno Nacional. Santiago de Chile, ago. 1983.

. El pueblo rebelde vencerá. Santiago de Chile, abr. 1985.

. Prólogo de una locura irresistible y del odio descontrolado del capitalismo, folleto producido desde Cárcel de Alta Seguridad. Santiago de Chile, oct. 1995.

PORTELLI, A. Las peculiaridades de la historia oral. In: BRAVO, J. (Ed.). Memoria histórica y sujeto popular. Santiago de Chile: ECO, 1987. p. 35-46.

RICHARD, N. Inconformistas rebeldes sin vuelta. El vértigo del grupo MAPU-Lautaro. Revista de Critica Cultural, n. 28, p. 66-73, jun. 2004.

SI HAY UN PARO tendrán que atenerse a las consecuencias". La Tercera, Santiago de Chile, 6 mayo 1983. Sin paginación.

TIRONI, E. La revuelta de los pobladores. Integracción social y democracia. Nueva Sociedad, n. 83, p. 24-32, mayo/jun. 1986.

VALENZUELA, E. La rebelión de los jóvenes. Santiago de Chile: Sur Ediciones, 1984.

Resumen: Esta ponencia tiene como objetivo analizar los orígenes de las Protestas Populares Nacionales que estallaron en Chile el 11 de mayo de 1983 bajo la dictadura militar del general Pinochet, a partir de la experiencia de los militantes del MAPU (Lautaro), quienes le dieron una proyección política a dichas jornadas y siguen teniendo la visión de que fueron más que un estallido debido a una crisis económica, ya que también hubo expresiones y organizaciones que nacieron desde el cese del sujeto popular y que desarrollaron nuevas formas de hacer políticas; pero a partir de un complejo proceso de cambio y continuidad del movimiento popular chileno.

Palabras clave: dictadura chilena, MAPU, Lautaro, movimientos sociales, transición política. 
“The people in flames". The origins and meanings of popular protest of 1983 from memory MAPU-Lautaro.

Abstract: The following paper is to analyze the origins of national protests that appeared
in Chile on May 11, 1993, under the military dictatorship of General Pinochet from the
experience of MAPU (Lautaro) militants, who gave such a screening policy to these events
and nowadays, they have a vision that was more than a summary report by an economic crisis,
but there were also expressions and organizations that were born from the case of the popular
subject and were developing new ways to make policies, but from a complex process of change
and continuity of Chilean popular movement.

Keywords: Chilean dictatorship, MAPU, Lautaro, social movements, political transition.

Recebido em 30/09/2012

Aprovado em 10/11/2012 